\title{
Andaimento: estratégia de aprendizado vivenciada em aulas de línguas estrangeiras
}

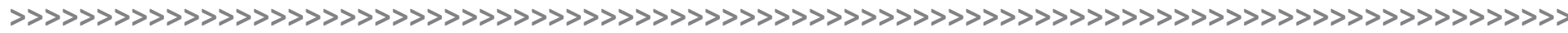

Gerônimo Loss Bergmann*

\section{Resumo:}

Este estudo qualitativo aborda a aprendizagem e o ensino da língua inglesa como Língua Estrangeira em uma escola pública regular de Ensino Médio em Porto Alegre. Entrevistas filmadas e análises interpretativas de dados coletados durante as aulas foram utilizadas como instrumentos metodológicos de pesquisa. O principal objetivo é a aprendizagem colaborativa dos alunos, isto é, durante as aulas, eles atuam como mediadores de seus próprios aprendizados, por meio de tarefas, tendo como base o andaimento, termo cunhado por Wood, Bruner e Ross (1976). Esta estratégia de aprendizado provém da teoria sociocultural iniciada por Vygotsky, filósofo bielorrusso e importante fonte teórica nesta pesquisa. Os resultados foram obtidos num período de três anos nessa escola pública regular que visa, além de um ensino de boa qualidade, à inserção do aluno em ambientes diferenciados que promovam aprendizagem.

\section{Palavras-chave:}

Ensino-aprendizagem. Mediação. Língua estrangeira. Linguagem.

\begin{abstract}
:
This qualitative study addresses the learning and teaching of English as a Foreign Language in a regular public school to high school students in Porto Alegre. Filmed interviews and interpretative analyzes of data, collected during the classes, were used as methodological tools. The main goal is the collaborative learning of the students during the classes; they work as mediators of their own learning throughout tasks. It is based on scaffolding, a term coined by Wood, Bruner and Ross (1976), which comes from sociocultural theory initiated by Vygotsky, Belarusian philosopher and relevant theoretical source in this research. The results were obtained over a period of three years in that regular public school that aims, in addition to a good education quality, the inclusion of students in different learning environments.
\end{abstract}

\section{Keywords:}

Teaching-learning. Mediation. Foreign language. Speech.
* > Bolsista de iniciação científica do projeto PIBIC do Conselho Nacional de Pesquisa (CNPq, 2012). Estudante do segundo ano do Ensino Médio. E-mail: geronimobergmann@hotmail.com. Maíra Barberena de Mello é a orientadora desta pesquisa. Ela é mestre em Letras pela UniRitter e é professora de Línguas Estrangeiras Língua Inglesa EBTT CAp-UFRGS. 


\section{Introdução}

O presente trabalho discorre sobre a análise da estratégia de ensino-aprendizagem observada e estudada em aulas de língua inglesa como Língua Estrangeira (LE) chamada andaimento, dentro de uma perspectiva da teoria sociocultural. A pesquisa qualitativa aborda etnograficamente as interações e a produção oral de alunos de uma turma de língua inglesa, em uma determinada escola pública. Ela se realiza em três partes: o suporte teórico, a comparação e argumentação de textos, e o desenvolvimento final, ou seja, os resultados do estudo realizado.

\section{Metodologia}

A filmagem de entrevistas auxiliou a análise dos dados da pesquisa, de modo que esta fosse feita de maneira coerente, com base na opinião e no entendimento de cada aluno entrevistado quanto ao andaimento (WOOD; BRUNER; ROSS, 1976), contribuindo para o êxito de sua construção. A análise interpretativa dos dados e do material de vídeo e de áudio pretende estimular a reflexão por parte de professores de LE quanto a uma determinada turma, no que se refere ao tipo de interação que favorece os alunos ao falar usando a língua inglesa. O estudo da produção oral em LE (fala em língua estrangeira) no Ensino Médio (EM) ainda necessita de estudos em escolas regulares. Além disso, é importante salientar que o processo de pesquisa foi investigado ao longo de aproximadamente três anos nas aulas de LE com alunos de uma determinada turma do EM.

\section{Análise dos dados}

Quanto às formas de aprender a língua inglesa, a maioria dos alunos citou ser importante o aprendizado por meio de diferentes metodologias, aplicadas às chamadas habilidades linguísticas que, por sua vez, são ler, escutar, falar e escrever. Isso abrange uma série de oportunidades de aprendizagem, que inclui assistir a filmes em inglês com legendas na língua-alvo (língua que se quer aprender), escutar músicas, mas, ao mesmo tempo, manter a presença da gramática e do aprendizado em sala de aula. Os referidos eventos de aprendizagem podem ser mediados tanto pelo professor como por um colega mais experiente em um aspecto de um conhecimento. Assim, o professor planeja uma atividade com um determinado grau de dificuldade e um colega também faz parte do processo de ensino-aprendizagem, promovendo, dessa forma, interações de um com o outro, para resolver uma situação desafiadora.

\section{Discussão}

Com minha autonomia quanto às discussões sobre a teoria sociocultural de Vygotsky ${ }^{2}$ (2003), interajo com o conhecimento existente em diferentes linguagens e conheço novos conceitos, os quais foram construídos culturalmente, de modo a participar das atividades mentais e sociais estabelecidas entre os indivíduos. A teoria sociocultural iniciada por Vygotsky, por sua vez, aponta que o conhecimento e a formação de certo indivíduo vem de fora para dentro, ou seja, as relações entre o indivíduo e o ambiente o constroem, pois são socialmente mediadas. 
Os estudos de Vygotsky (2003) mostram que, em certo ponto, o desenvolvimento de um aluno pode ser facilitado pela sua zona de desenvolvimento proximal (ZDP), um local metafórico em que formas de mediação se desenvolvem entre os pares gerando aprendizado. Esse local metafórico é um local dinâmico, em que trocas que acarretam aprendizagem podem ocorrer constantemente nas duplas. A importância da ZDP deve-se ao benefício proveniente da interação e da mediação, e, nesse processo, os alunos recebem esse auxílio tanto de seu professor como de um parceiro mais experiente em um conhecimento/uma habilidade, o qual também aprende, construindo um diálogo colaborativo que gera aprendizagem. Acerca da aprendizagem, Vygotsky afirma que:

Ela é a distância entre o nível de desenvolvimento real, que se costuma determinar através da solução independente de problemas, e o nível de desenvolvimento potencial, determinado através da solução de problemas sob a orientação de um adulto ou em colaboração com companheiros mais capazes (VYGOTSKY, 2003, p. 112).

Para Vygotsky (2003), uma característica importante no processo de aprendizagem é a ocorrência da ZDP, pois somente a partir da interação e da cooperação alguns processos de desenvolvimento podem ser realizados.

Nessas situações, os indivíduos têm oportunidade de interagir e de participar de uma cadeia comunicativa que permite a variação de discursos. Uma noção essencial para a teoria sociocultural é o fato de o aprendizado e o desenvolvimento ocorrerem conforme as pessoas participam de atividades socioculturais em suas comunidades. Nesse sentido, as tarefas de sala de aula são também vistas como atividades que promovem engajamento social. (LIMA; COSTA, 2012)

Estimulando a comunicação na língua-alvo, o professor pode criar um propósito para o uso da linguagem e oferecer um contexto natural para o estudo dela pelo aluno, a fim de atingir um resultado. O papel do professor na mediação é o de selecionar tópicos e tarefas que irão motivar seus alunos, oferecendo-lhes desafio linguístico, para que haja desenvolvimento na língua-alvo. A língua torna-se, então, um veículo para atingir resultados nas tarefas, e a ênfase está no significado e na comunicação.

\section{Considerações finais}

Do meu ponto de vista quanto ao assunto, aponto a estratégia de aprendizado andaimento, abordada nos estudos realizados segundo a teoria sociocultural iniciada por Vygotsky, como uma versão coerente do significante aprendizado, ou seja, esta é a palavra que parece melhor se adequar ao que este evento representa no processo de aprendizagem. Penso assim, pois a ideia proposta pelo autor da teoria sociocultural é que os alunos aprendam cooperativamente, na medida em que associam termos recém-aprendidos como uma ajuda para a vida, auxiliando-os, dessa forma, nos momentos menos esperados. O conceito de andaime é justamente este: o conhecimento cresce com a transposição de um espaço para outro mais elevado, como os novos andares que estão sendo construídos, bem como a capacidade de resolver desafios.

Fiz parte da pesquisa, como bolsista, e, também, como um aluno aprendo uma LE. Além disso, aprendo nas situações oferecidas pelo Colégio de Aplicação da Universidade Federal do Rio Grande do Sul (UFRGS), como no projeto Drama Club ${ }^{3}$, nos intercâmbios oferecidos para os alunos, assim como no meio online - em que se faz comunicação em diferentes línguas de forma oral e escrita.

Dessa forma, como um amante de línguas estrangeiras, percebo, cada dia mais, que posso tentar exemplificar e provar como verdadeiras as percepções de Vygotsky.

3 > Drama Club: projeto extracurricular do Colégio de Aplicação da UFRGS que trabalha teatro e línguas estrangeiras. 
Em se tratando dos aprendizados já tidos antes da pesquisa, entendo o estudo vygotskyano da forma que é explicado, no que se refere à formação segundo as influências do meio, visto que é feita uma associação com base na dissertação. Isto é, qualquer tipo de relação cooperativa que já tenha ocorrido com algum colega linguisticamente mais capaz - sem que se tenha percebido - ou um auxílio que se tenha prestado a outro colega contribuiu para a minha formação linguística, uma vez que a língua medeia a aprendizagem da própria língua, a partir da resolução de problemas linguísticos.

Espera-se, portanto, que essa pesquisa incentive a utilização de tarefas colaborativas que propiciem momentos de engajamento social e cognitivo em sala de aula, de modo a favorecer o processo de autonomia dos aprendizes.

O aprendizado que se desenvolveu durante a pesquisa também se torna um grande resultado de sua realização. Dessa forma, pode-se associar os conhecimentos que foram adquiridos também a outros idiomas, como a língua alemã, tendo como produto final diversos significados que foram aprendidos e que serão levados para a conclusão de futuros objetivos, como uma pesquisa a ser realizada com base nesta experiência.

Através dos artigos que li e das relações que foram feitas no desenvolvimento desta pesquisa, percebo, mais ainda, o quão engajado me sinto para aprender novos idiomas, novas linguagens. O estímulo da comunicação na língua-alvo entre os aprendizes torna-se algo completamente propício e auxilia o processo de ensino-aprendizagem dos estudantes. (LIMA; COSTA, 2010)

Novas linguagens, novas escritas, novos conhecimentos: tudo a serviço de um novo aprendizado. A facilidade que tenho em me mover para diferentes ambientes de estudos me transportou também à ciência e à concretização de teorias como a da estratégia de aprendizagem andaimento, relacionando-as com cada aprendizado tido durante a realização da pesquisa. Pretendo me engajar cada vez mais em novas realidades, às quais sempre procurarei me posicionar, realizando novas descobertas.

\section{Referências}

LIMA, Marília; COSTA, Patrícia. Estudos sobre aprendizagem colaborativa em língua estrangeira: relações de pesquisa no contexto brasileiro e canadense. In: Interfaces Brasil/Canadá, v. 1, p. 143-156, jan./jun. 2010. Disponível em: http://www.revista becan.com.br/arquivos/1277642312. pdf. Acesso em: 10 jan. 2013.

MELLO, Maíra Barberena. Interações e a produção oral em língua adicional em uma escola pública. 2011, 115 fs. Dissertação (Mestrado em Letras) - Programa de Pós-Graduação em Letras, Centro Universitário Ritter dos Reis, Porto Alegre, 2011.

WOOD, David; BRUNER, Jerome Seymour; ROSS, Gail. The role of tutoring and problem solving. In: Journal of child psychology and psychiatry, v. 17, p. 89-100, 1976.

VYGOTSKY, Lev Semenovitch. A formação social da mente. São Paulo: Martins Fontes, 2003. 